\title{
Positive impact of recreational techniques for the self-healing of the body
}

\author{
O impacto positivo das técnicas recreativas \\ do autorestabelecimento do corpo
}

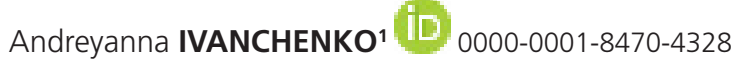

\begin{abstract}
The aim of this study was to evaluate the effectiveness of Reiki (as well as the effectiveness of Physical Activities) on relatively healthy individuals (not hospital patients), members of a sample of 338 volunteers, and to confirm whether practicing Reiki contributes to psycho-emotional stabilization, having a beneficial impact on mood and emotional wellbeing. For the first time, a positive confirmation of Reiki was carried out in Ukraine. The respondents were divided into two main groups: non-Reikists (individuals who did not practice Reiki) and Reikists (individuals who practiced or taught Reiki). It was found that, in comparison with non-Reikists, the results obtained by Reikists were twice as good, showing higher levels of emotional comfort, less anxiety/dissatisfaction, and more optimism, energy and self-confidence. At that, senior pupils and university students of psychology performed worse. This study confirms that the practice of Reiki is a quickly healing, stimulating, long-term, and cost-effective technique, positively influencing to positive well-being, mood and psychosomatic responses.
\end{abstract}

Keywords: Anxiety; Mental health; Mind-body therapies; Psychophysiology.

\section{Resumo}

O objetivo deste estudo foi identificar a eficácia do Reiki (assim como da atividade física) para pessoas relativamente saudáveis (não pacientes hospitalares) numa amostra de 338 participantes e confirmar que a prática do Reiki contribui para a estabilização psicoemocional, tem um efeito benéfico no humor e bem-estar. Pela primeira vez, uma confirmação positiva do Reiki foi realizada na Ucrânia. Os entrevistados foram divididos em dois grupos principais: não Reikistas (que não praticavam Reiki) e Reikistas (que praticavam ou ensinavam métodos de Reiki a outros). Foi descoberto que, sendo comparados aos não-Reikistas, os resultados dos Reikistas foram duas vezes melhores, revelando um nivel mais alto do conforto emocional, menos ansiedadelinsatisfação e mais otimismo, energia e autoconfiança. Ao mesmo tempo, alunos dos últimos anos de escolaridade assim como estudantes de especialidades psicológicas apresentaram os piores resultados. Este estudo confirma que a prática de Reiki é um método de recuperação rápida, estimulante, de longo prazo e economicamente eficaz que tem influência positiva no bem-estar, o humor e o estado psicossomático de uma pessoa.

Palavras-chave: Ansiedade; Saúde mental; Terapias mente-corpo; Psicofisiologia.

\footnotetext{
T.

1 Kharkiv Institute Interregional Academy of Personnel Management, Department of Psychology. Beketova st., Kharkiv, 61007, Ukraine. E-mail: <andreyan@libero.it>.

$\boldsymbol{\nabla} \mathbf{v}$

How to cite this article

Ivanchenko, A. (2020). Positive impact of recreational techniques for the self-healing of the body. Estudos de Psicologia (Campinas), 37, e190082. http://dx.doi.org/10.1590/1982-0275202037e190082
} 
Over the past decades, the popularity and spread of psychosomatic strengthening techniques for the self-healing of the body (Reiki, Yoga, Qigong, meditation, Tai Chi, Karate, sports versus sedentary behavior, and many others) are growing in popularity among the population. Within this premise, public interest in the use of complementary and alternative medicine has sharply increased as well. This trend could not fail to attract the attention of scientists from different specialties: physicians, psychologists, researchers, practitioners, and even philosophers who conducted several studies of the data obtained while using ancient East Asian techniques, both for normalizing psychosomatic disorders and for restoring physical condition, having received a vivid confirmation that these methods may effectively function as a healing art for warding off diseases, and enhancing the overall health state of the individual (Amirova, Cropley, \& Theadom, 2017; Fuzhong \& Harmer, 2014; Reifsteck \& Brooks, 2018; West, Liang, \& Spinazzola, 2017). Both the Reiki art and other Ancient Oriental self-healing techniques, as well as different recreational activities (various sports, dancing, reading), act as protective internal mechanism, producing a great beneficial effect (Ivanchenko \& Zaika, 2017; Kovács, 2018; Rezaei \& Khosroshahi, 2018).

The interest of the global scientific community to additional self-healing methods of restoring, healing and recreating the human body is not accidental. As the reality of life shows us, stress has become a constant (but undesirable) companion in a person's life everywhere. In Ukraine, a country that has experienced, in recent years, major socio-economic difficulties and is partially now in a state of war, the economic and social instability, different forms of stress, various problems (cognitive, behavioral, emotional and physiological) lead to a more negative life background for the present-day youth. Trying to self-protect, students use ineffective and even anti-social means of reducing stress, such as alcohol, smoking, a sedentary lifestyle, spending too much time on TV or Internet, and avoiding physical activities (Ivanchenko, Timchenko, \& Zaika, 2018). Instead of this, it should be necessary to practice more different kinds of sport, cognitive-developmental training, relaxation and making-healthy techniques, which aim to improve healing qualities of individuals and increase their resistance to stress. Accordingly, already at an early age, a person is able to form intrinsic stability, which includes such indispensable components as prognostic abilities, stable reasons, life perspectives, goals and needs, reference points for self-improvement, adaptive-resource potential and self-control that, as a whole, contribute to the promotion of their recreational and mobilization potential, formation of axiologically oriented personal qualities, and sustainable motivation for self-development (Norchuk \& Lunov, 2016; Tsekhmister \& Lysenko, 2018). The individual's personal values and their connection with social, ethical, bio-psychological factors of this person's activities, in many aspects, predetermine the path of his or her self-development, selfrealization, approaching to their own acme and promoting an individual creative life orientation, that in total can promote positive behavior, sense of belonging and knowledge exchange in order to achieve common goals; in this case, permanent development throughout a person's life, transforming this individual in the model of the deterministic process (Farias, Hastie, \& Mesquita, 2017; Ivanchenko, 2017).

Any physical and mental overexertion can cause physiological disorders, worsen memory, decline the dynamics of thinking and intellection processes, as well as significantly reduce the positive effect of physical activities (Chang et al., 2017). Consequently, in the conditions of excessive psycho-physical tension and exhaustion, the creation of a suitable stimulating environment, benevolent interpersonal atmosphere, intensification of positive emotions, the use of Reiki, Yoga, meditation, Tai Chi, acupressure, massage and other complementary techniques may provide a quick normalization of human organism functions, enhance personal potential and physical activities, ensuring a sense of self-realization, self-efficacy and self-confidence. It is precisely because of their obvious positive influences that the popularity of Ancient Eastern practices is growing. A confirmation of this may be the fact that Reiki, in particular, has been used as an auxiliary and additional method of self-healing and rehabilitation in clinics and medical centers: the administrations of hundreds of hospitals in Japan and the United States officially introduced Reiki techniques into the treatment

2 of their patients. 


\section{Introduction to the field of study}

Systematic, intensive and increasingly complex studies of the effects of Reiki techniques are being conducted nowadays in Japan (and other Asian countries), the United States of America, Australia, Latin America and Europe. The vast majority of them continue to confirm the positive effect of Reiki in various areas of clinical practices (oncology, cardiology, postoperative rehabilitation, bone surgery, psychotherapy, endoscopy, and others) and reinforce that Reiki therapy is effective for pain and anxiety, positively affects mood, body and mind, with healing effects, provides emotional and spiritual balance, reduces work-related stress, helps in managing occupational burnouts, improves intrinsic comfort, well-being and health, reduces depression, and may be used as a means of self-care (Birocco et al., 2012; Erdogan \& Cinar, 2016; Midilli \& Gunduzoglu, 2016; Notte, Fazzini, \& Mooney, 2016; Salles, Vannucci, Salles, \& Da Silva, 2014; Thrane \& Cohen, 2014).

Reiki has been found to be an effective complementary therapy that can be implemented alongside all other medical and therapeutic techniques (Baldwin, Vitale, Brownell, Krejak, \& Rand, 2017), showing significant improvements in the emotional, physical, psychological, and social dimensions. Furthermore, according to the neurovisceral integration model and the polyvagal theory, the positive effects of Reiki are due to higher parasympathetic nervous system activity, mediated via the vagus nerve (McManus, 2017).

The vast majority of research results were obtained from clinic patients, reinforcing the effectiveness of Reiki techniques. According to the opinion of the researchers of this study, it is more important to carry out investigations on healthy participants, so that (with the help of Ancient Eastern practices of self-healing, including Reiki) it is possible to prevent, in healthy individuals, psycho-physiological negative symptoms that already require medical intervention. Unfortunately, there are only episodic studies performed on healthy volunteers, but they also confirm that groups receiving Reiki treatment interventions show higher overall mood scores, a decrease in disease symptoms, a significant reduction in self-perceived stress, and improved subjective well-being, which was not observed in non-Reiki participants (Bowden, Goddard, \& Gruzelier, 2010; Bowden, Goddard, \& Gruzelier 2011; Vasudev \& Shastri, 2017). This fact points out the relevance and need of such studies. This research follows this approach.

\section{Applying East Asian techniques in post-Soviet countries}

The overwhelming majority of studies in the world has positively assessed Reiki techniques. Unfortunately, scientists of the largest post-Soviet countries (Ukraine, Russia, Belarus, Moldova), until the present moment, have not carried out any scientific studies that study the influence of the use of Ancient Eastern techniques/practices on the healing of psycho-physiological status and self-healing of the human organism. The same applies for scientific verification (positive or negative) of Reiki effects. Therefore, there are no scientific journals in these countries that publish original articles as to this topic. Although, as for Ukraine, ancient oriental techniques (meditation, Yoga, Reiki, Qigong, and others) are often included in psychotherapeutic treatments, which are performed according to the traditional scheme. However, studies with a qualitative and quantitative analysis of their influence on the human body are still absent in the Ukrainian scientific literature. There are only separate scientific articles in which the authors sometimes note the positive effect of their use, but without any statistical confirmation. At the same time, for several decades, in almost all large post-Soviet countries the dissemination of the Reiki system was provided only through mass media, the Internet, and individual sessions: now Reiki training is being successfully carried out in Reiki schools and specialized centers. The results of their activity irrefutably testify to the usefulness of the application of Reiki techniques due to the improvement of health and social activities of Reiki-involved individuals. 
This study is the first scientific systematized investigation of the impact of Reiki, carried out in a Ukrainian sample and aimed to confirm the positivity of the impact of Reiki on the psychosomatic and social sphere of human life.

\section{Hypothesis and objective of the study}

The main hypothesis of this study is based on the assumption that the practice of Reiki helps to reduce the response to stress, overstrain and fatigue in healthy people (both in young and adult individuals). Based on our review of recent world investigations focused on studying Reiki, the expectations of the researchers of this study can be summarized, embodied in the following working hypotheses. Reikists (participants involved with the practice of Reiki) are expected to have much higher psycho-physiological and somatic indicators than non-Reikists. Age indicators are associated with higher experience and logic behavior scores that could offer a psychological shelter, but lower level of health, as the age increases. From such suggestion, it is expected that the age factor is not a determinant, and Reikists will have better scores when compared to other categories of participants, since they are more psycho-emotionally protected.

The aim of the present study was to compare the psycho-physiological indicators of health, mood and personal well-being between Reikists and non-Reikists (students; banking professionals; research institute staff, namely, scientists-physicists and administrative-technical staff). The study was conducted in 3 stages, focused on the following tasks: (1) to compare the psycho-physiological indicators of health, mood and personal well-being of all groups, without taking into account the age variable; (2) to identify the effect of age and gender factors on the psycho-physiological indicators of health; and (3) to determine the group with the best psycho-physiological and psycho-emotional health indicators.

\section{Method}

This study was conducted in accordance with the directives of the Experts on Ethics of the Kharkiv Institute - "Interregional Academy of Personnel Management", the research project was previously approved at the Research Ethics Committee, protocol number 12/5-09 on December 17th, 2018.

\section{Participants}

The sample consisted of 338 Ukrainians (116 men and 222 women), aged 16-69, relatively healthy, who were not hospital patients, of different professional categories, for a more extensive and objective analysis of the results: young people of different specializations (senior pupils and university students) and adults (banking professionals and research institute staff). They were informed about the goals and objectives of the study, gave written permission to participate and, by February 2019, completed the psychological self-assessment, which was composed of two questionnaires. According to the socio-demographic characteristics, all participants were identified by the following categories, named as follows: (1) Schoolchildren (senior pupils); (2) Humanities students (students of psychology, sociology, law and economics); (3) Athletes (physical educators and students involved with sports); (4) Research institute staff: (i) scientists-physicists, (ii) administrative-technical staff; (5) Banking professionals (heads, managers, cashiers, technical staff); (6) Reikists (participants who studied Reiki techniques, or those who taught this technique). The participants were divided into two main groups: non-Reikists (who did not practice Reiki) and Reikists (who used Reiki techniques on themselves, as well as those who taught this technique). The main two groups (non-Reikists and Reikists) included participants of comparable professional specifications and approximately of the same age (from 16 to 45 years old and above). 
The inclusion criteria for participants were as follows: (a) studying in a high school or university, (b) working in the banking sector, (c) working in the research environment, (d) from 17 to 65 years old, (e) it did not make a difference whether they were married or not, $(f)$ all participants signed a written consent and were willing to cooperate in experiments. The exclusion criteria were as follows: (a) presence of any chronic physical illness or mental disorder, (b) unemployment, (c) alcoholism or drug addiction, (d) exposure to any kind of medical or behavioral intervention during last year.

\section{Instruments}

Two instruments were used in this study for measuring the psycho-physiological state and internal well-being of a person: (1) The State-Trait Anxiety Inventory (STAI), designed by C.D. Spielberger in 1966 (V.F. Berezin performed its Russian-language standardized adaptation in 1967), which is a self-reported instrument commonly used to assess levels of state anxiety and trait anxiety through 40 items in a Likert Scale. In this study, only the STAI Form Y-1 (20 items) was used, which was considered enough, since the statements in the Form Y-1 do not refer exclusively to a present moment but also relate to recent events which are stored in memory such as experiences and feelings. All items in STAI Form Y-1 are rated on a 4-point scale, where a participant assesses the intensity of his current feeling as follows: 1 = "Not at all", 2 = "A little", 3 = "Moderately", and 4 = "Very much", and (2) The Scale of Subjective Well-Being (SSWB) was developed by Anne Perrudet-Badoux in 1988, Maria Vasilievna Sokolova fulfilled its Russian-language standardized adaptation in 1992 (Perrudet-Badoux, Mendelsohn, \& Chiche, 1988; Sokolova, 1996). This Scale is a psycho-diagnostic instrument for measuring the emotional component of subjective well-being, namely: the quality of emotional comfort (or experiences), moods and the subjective well-being of the individual, ranging from optimism, energy and self-confidence to depression, irritability and loneliness. For each of the 17 statements, participants had to indicate how much they agreed or disagreed using the Likert 7-point scale, which ranges from strong agreement to complete disagreement. They were to choose their answers by marking one of the options available in the seven columns, which most accurately determines their sensations, feelings, life perception, and attitude to life situations, highlighting the number corresponding to their answer (namely: 1 - "I fully agree", 2 - "I agree", 3 - "I more or less agree", 4 - "I find it difficult to answer", 5 - "I more or less disagree", 6 - "I disagree", 7 - "I completely disagree").

All respondents first received a STAI Form Y-1 with 20 items, and then they were instructed to complete the SSWB questionnaire with 17 statements. For both questionnaires, all received indicators (in summarized "raw scores") were determined by means of the Table of Key Responses, and then converted in Anxiety (for STAI) and Well-Being (Stan) scores (for SSWB); Stan is a standard estimated value of the total sum of the "raw scores". Presently the Alpha Cronbach's value for STAI and SSWB questionnaires are 0.713 and 0.827 , respectively.

\section{Processing of statistical data}

When interpreting the indicators obtained with the STAI Form $Y-1$, the following anxiety scores were used: "raw score" until 30 - low, 31-44 - moderate; 45 and over - high. Very high anxiety (> 46) can be associated with the presence of an internal neurotic conflict, emotional breakdowns, and even psychosomatic diseases. Low anxiety $(<12)$, on the contrary, characterizes the condition as depressive, inactive, with a low level of motivation. Sometimes very low anxiety in test scores is a result of the fact that some individuals actively try to suppress high anxiety levels in order to show themselves in a "more positive way".

The indicators of emotional subjective well-being obtained with the SSWB are determined using following the Key Responses for Stan data interpretation, namely: Stan 1 ("raw score" between 25-35) 
characterizes complete emotional comfort and well-being; Stan 2 (36-40) and 3 (44-48) - moderate emotional comfort; Stan 4 (49-55), 5 (56-62), 6 (63-70) and 7 (71-77) - moderate subjective well-being with insignificant issues but no serious problems; Stan 8 (78-85) and 9 (86-92) - a person who is pessimistic/reticent, poorly enduring stressful situations, prone to internal anxiety and depression; Stan 10 (93-100) - significantly evident emotional discomfort.

\section{Results}

As expected in the hypothesis stage, the practice of Reiki has evidenced much better psycho-physiological and emotional indicators than the participants who did not practice Reiki techniques. So, according to the Average-arithmetic Value of the summed "raw scores" obtained in STAI and SSWB for each group of participants depending on the age factor, the data of Reikists, banking professionals and Research institute staff are much better than those of senior pupils and university students. Among participants in youth groups (senior pupils and university students), athletes showed less dissatisfaction, anxiety or emotional discomfort, while senior pupils demonstrated the highest degree of anxiety and the highest (problematic) level of emotional well-being. In general, the indicators of psychologists, sociologists, economists, and lawyers vary very slightly between themselves, but the group of the psychologists was unexpectedly ahead among the youth groups more likely to react negatively to stressful situations which threaten a self-esteem or personal adequacy.

\section{Data Analyses}

The above established general trend is also visible while analyzing the influence of the age and gender factors on the psycho-physiological and emotional indicators.

According to the following, from the analysis of the influence of the age factor presented in Table 1 , senior pupils (the youngest participants) had the highest degree of anxiety (STAI) and the lowest level of emotional well-being (SSWB). As for the student groups, the best results (being improved with age) were among athletes. It is important to emphasize that only a single group of participants (Reikists) had a positive tendency in both the STAI and the SSWB, namely: despite the fact that, with age, anxiety rises insignificantly and the psycho-emotional state worsens, nevertheless, all their indicators are much better than those in the other groups. In general, it can be stated that, among all groups of participants, the age factor has no unambiguous correlation with either the level of anxiety or emotional well-being.

Table 1

Participants' scores regarding the SSWB and STAI means, according to the age factor

\begin{tabular}{|c|c|c|c|c|c|}
\hline \multicolumn{2}{|c|}{ Participants $(n=338)$} & \multicolumn{4}{|c|}{ Instruments } \\
\hline \multirow{2}{*}{$\begin{array}{l}\text { Professional specification and } \\
\text { activity (studying/work) }\end{array}$} & \multirow{2}{*}{$\begin{array}{c}\text { Age } \\
\text { (years old) }\end{array}$} & \multicolumn{2}{|l|}{ STAI (Form Y-1) } & \multicolumn{2}{|l|}{ SSWB } \\
\hline & & $\begin{array}{l}\text { Average-arithmetic value of } \\
\text { the summed "raw score" }\end{array}$ & $\begin{array}{c}\text { Anxiety } \\
\text { scores }\end{array}$ & $\begin{array}{l}\text { Average-arithmetic value of } \\
\text { the summed "raw score" }\end{array}$ & Stan \\
\hline Schoolchildren & $16-18$ & 73.0 & high & 50.4 & 4 \\
\hline \multicolumn{6}{|l|}{ Humanities students } \\
\hline \multirow[t]{2}{*}{ Psychologists } & $17-20$ & 62.9 & high & 42.3 & 3 \\
\hline & $21-24$ & 64.7 & high & 49.7 & 4 \\
\hline Sociologists & $17-20$ & 63.3 & high & 46.4 & 4 \\
\hline \multirow[t]{2}{*}{ Economists } & $17-20$ & 59.0 & high & 52.8 & 4 \\
\hline & $21-24$ & 59.7 & high & 47.0 & 3 \\
\hline \multirow[t]{2}{*}{ Lawyers } & $17-20$ & 62.6 & high & 47.0 & 3 \\
\hline & $21-24$ & 59.5 & high & 44.9 & 3 \\
\hline
\end{tabular}


Participants' scores regarding the SSWB and STAI means, according to the age factor

\begin{tabular}{|c|c|c|c|c|c|}
\hline \multicolumn{2}{|l|}{ Participants $(n=338)$} & \multicolumn{4}{|c|}{ Instruments } \\
\hline \multirow{2}{*}{$\begin{array}{l}\text { Professional specification and } \\
\text { activity (studying/work) }\end{array}$} & \multirow{2}{*}{$\begin{array}{c}\text { Age } \\
\text { (years old) }\end{array}$} & \multicolumn{2}{|l|}{ STAI (Form Y-1) } & \multicolumn{2}{|l|}{ SSWB } \\
\hline & & $\begin{array}{l}\text { Average-arithmetic value of } \\
\text { the summed "raw score" }\end{array}$ & $\begin{array}{l}\text { Anxiety } \\
\text { scores }\end{array}$ & $\begin{array}{l}\text { Average-arithmetic value of } \\
\text { the summed "raw score" }\end{array}$ & Stan \\
\hline \multirow[t]{3}{*}{ Athletes } & $17-20$ & 57.4 & high & 39.9 & 2 \\
\hline & $21-24$ & 55.6 & high & 37.8 & 2 \\
\hline & $25-33$ & 32.0 & moderate & 25.0 & 1 \\
\hline \multicolumn{6}{|l|}{ Research institute staff } \\
\hline \multirow[t]{3}{*}{ Scientists-physicists } & $25-33$ & 43.6 & moderate & 39.4 & 2 \\
\hline & $34-44$ & 48.6 & high & 40.3 & 2 \\
\hline & 45 or over & 48.2 & high & 41.0 & 3 \\
\hline \multirow[t]{3}{*}{ Administrative-technical staff } & 25-33 & 73.0 & high & 53.0 & 4 \\
\hline & $34-44$ & 50.3 & high & 40.5 & 2 \\
\hline & 45 or over & 59.5 & high & 44.9 & 3 \\
\hline \multirow[t]{3}{*}{ Banking professionals } & $21-24$ & 49.0 & high & 33.0 & 1 \\
\hline & $25-33$ & 48.0 & high & 33.2 & 1 \\
\hline & $34-44$ & 38.8 & moderate & 36.8 & 2 \\
\hline \multicolumn{6}{|l|}{ Reikists } \\
\hline \multirow[t]{2}{*}{ Students } & $17-20$ & 24.5 & low & 27.0 & 1 \\
\hline & $21-24$ & 28.6 & low & 27.2 & 1 \\
\hline \multirow[t]{3}{*}{ Workers } & $25-33$ & 36.0 & moderate & 32.1 & 1 \\
\hline & $34-44$ & 30.3 & low & 28.7 & 1 \\
\hline & 45 or over & 39.9 & moderate & 34.1 & 2 \\
\hline
\end{tabular}

Note: SSWB: Scale of Subjective Well-Being; STAI: State-Trait Anxiety Inventory.

According to the analysis of the influence of the gender factor, presented in Table 2, the differences in the average-arithmetic values of STAI indicators in each group varied between 0.2-9.4, with the smallest differences found in sociologists, and the highest in research institute staff. Differences in the average-arithmetic values for SSWB indicators ranged from 0.4 to 9.6, with the smallest differences found in psychologists, and the highest in banking professionals. Groups of male senior pupils, and females of the Reikist group, athletes, research institute and banking professionals had the worst results both in the STAI and SSWB, compared with those of the opposite sex. The other groups did not show such a coincidence, namely: according to the STAI indicators, male participants had worse results than female participants had, while the reverse trend was observed in the SSWB indicators.

Table 3 presents the summarized indicators regarding the STAI and SSWB scores of the non-Reikist and Reikist groups which reveal that the results of the Reikist group are significantly better as to the degree of anxiety and the level of subjective emotional well-being. These results were discriminated in generalized indicators for each of these two groups and according to the age and gender factors.

As it was requested in the procedure, all non-Reikists were also required to provide additional information about their sports and other hobbies, including Reiki itself. There were 12 such participants, among which: some were engaged in various sports (Karate, horse riding, swimming, volleyball, Tai Chi), others practiced Reiki (1 participant), Yoga, meditation, dancing and drawing. Their results, both in the STAI and the SSWB, indicated a low anxiety degree and a high level of emotional well-being. 
Table 2

Participants' results regarding the SSWB and STAI means, according to the gender factor

\begin{tabular}{|c|c|c|c|c|c|c|}
\hline \multicolumn{3}{|l|}{ Participants $(n=338)$} & \multicolumn{4}{|c|}{ Instruments } \\
\hline \multirow[b]{2}{*}{$\begin{array}{l}\text { Professional specification and activity } \\
\text { (studying / work) }\end{array}$} & \multicolumn{2}{|c|}{ Gender } & \multicolumn{2}{|c|}{ STAI (Form Y-1) } & \multicolumn{2}{|l|}{ SSWB } \\
\hline & M & $\mathrm{F}$ & $\begin{array}{l}\text { Average AV of the } \\
\text { summed "raw score" }\end{array}$ & $\begin{array}{l}\text { Anxiety } \\
\text { scores }\end{array}$ & $\begin{array}{l}\text { Average AV of the } \\
\text { summed "raw score" }\end{array}$ & Stan \\
\hline Schoolchildren $(n=15)$ & 8 & 7 & $\begin{array}{l}74.5 \\
71.3\end{array}$ & $\begin{array}{l}\text { high } \\
\text { high }\end{array}$ & $\begin{array}{l}52.5 \\
48.0\end{array}$ & $\begin{array}{l}4 \\
3\end{array}$ \\
\hline \multicolumn{7}{|l|}{ Humanities students } \\
\hline \multirow[t]{2}{*}{ Psychologists $(n=58)$} & 8 & & 59.1 & high & 43.8 & 3 \\
\hline & & 50 & 64.8 & high & 43.4 & 3 \\
\hline \multirow[t]{2}{*}{ Sociologists ( $n=47$ ) } & 15 & & 63.5 & high & 47.1 & 3 \\
\hline & & 32 & 63.7 & high & 46.0 & 3 \\
\hline \multirow[t]{2}{*}{ Economists $(n=11)$} & 2 & & 60.0 & high & 42.0 & 3 \\
\hline & & 9 & 59.3 & high & 50.7 & 4 \\
\hline \multirow[t]{2}{*}{ Lawyers $(\mathrm{n}=29$ ) } & 10 & & 55.8 & high & 46.8 & 3 \\
\hline & & 19 & 63.9 & high & 43.1 & 3 \\
\hline \multirow[t]{2}{*}{ Athletes $(n=45)$} & 21 & & 54.1 & high & 37.1 & 2 \\
\hline & & 24 & 58.8 & high & 41.3 & 3 \\
\hline \multirow[t]{2}{*}{ Research institute staff ( $n=60)$, among which: } & 21 & & 46.7 & high & 38.3 & 2 \\
\hline & & 39 & 56.1 & high & 42.7 & 3 \\
\hline \multirow[t]{2}{*}{ Scientists-physicists } & 20 & & 45.4 & high & 37.7 & 2 \\
\hline & & 10 & 50.9 & high & 36.8 & 2 \\
\hline \multirow[t]{2}{*}{ Administrative-technical staff } & 1 & & 73.0 & high & 51.0 & 4 \\
\hline & & 29 & 58.0 & high & 44.7 & 3 \\
\hline \multirow[t]{2}{*}{ Banking professionals $(n=10)$} & 4 & & 39.7 & moderate & 29.2 & 1 \\
\hline & & 6 & 46.0 & high & 38.8 & 2 \\
\hline \multirow[t]{2}{*}{ Reikists ( $n=63$ ), among which: } & 27 & & 32.6 & moderate & 30.2 & 1 \\
\hline & & 36 & 37.6 & moderate & 32.8 & 1 \\
\hline \multirow[t]{2}{*}{ Students } & 10 & & 27.8 & low & 27.1 & 1 \\
\hline & & 2 & 28.5 & low & 27.5 & 1 \\
\hline \multirow[t]{2}{*}{ Workers } & 17 & & 35.4 & moderate & 32.1 & 1 \\
\hline & & 34 & 38.1 & moderate & 31.2 & 1 \\
\hline
\end{tabular}

Note: AV: Average-arithmetic Value; SSWB: Scale of Subjective Well-Being; STAI: State-Trait Anxiety Inventory.

Table 3

STAI and SSWB summarized results of the Reikists and non-Reikists groups

\begin{tabular}{|c|c|c|c|c|}
\hline \multirow[b]{2}{*}{ Participants $(n=338)$} & \multicolumn{4}{|c|}{ Instruments } \\
\hline & $\begin{array}{l}\text { AV of the STAI - } \\
\text { "raw score" (Anxiety } \\
\text { score) in points }\end{array}$ & $\begin{array}{l}\text { AV of the SSWB - } \\
\text { "raw score" (Stan) } \\
\text { in points }\end{array}$ & $\begin{array}{l}\text { AV of the STAI - } \\
\text { "raw score" (Anxiety } \\
\text { score) in points }\end{array}$ & $\begin{array}{l}\text { AV of the SSWB - } \\
\text { "raw score" (Stan) } \\
\text { in points }\end{array}$ \\
\hline \multirow[t]{2}{*}{ Whole group of non-Reikists $(n=275)$} & 44 & 59 & & \\
\hline & (moderate) & (Stan 5) & & \\
\hline \multirow[t]{2}{*}{ Whole group of Reikists $(n=63$ ) } & & & 30 & 35 \\
\hline & & & (low) & $(S \tan 1)$ \\
\hline \multicolumn{5}{|c|}{ Indicators according to the age factor } \\
\hline \multirow[t]{2}{*}{ Non-Reikists between $16-24$ years old $(n=205)$} & 60.6 & 44.65 & & \\
\hline & (high) & $(S \tan 3)$ & & \\
\hline \multirow[t]{2}{*}{ Reikists between $16-24$ years old $(n=12)$} & & & 26.55 & 27.1 \\
\hline & & & (low) & $(S \tan 1)$ \\
\hline \multirow[t]{2}{*}{ Non-Reikists between 25-44 years old $(n=33)$} & 47.75 & 38.31 & & \\
\hline & (high) & $(S \tan 2)$ & & \\
\hline
\end{tabular}




\begin{tabular}{|c|c|c|c|c|}
\hline \multirow[b]{2}{*}{ Participants $(n=338)$} & \multicolumn{4}{|c|}{ Instruments } \\
\hline & $\begin{array}{l}\text { AV of the STAI - } \\
\text { "raw score" (Anxiety } \\
\text { score) in points }\end{array}$ & $\begin{array}{c}\text { AV of the SSWB - } \\
\text { "raw score" (Stan) } \\
\text { in points }\end{array}$ & $\begin{array}{l}\text { AV of the STAI - } \\
\text { "raw score" (Anxiety } \\
\text { score) in points }\end{array}$ & $\begin{array}{l}\text { AV of the SSWB - } \\
\text { "raw score" (Stan) } \\
\text { in points }\end{array}$ \\
\hline \multirow[t]{2}{*}{ Reikists between $25-44$ years old $(n=20)$} & & & 33.15 & 30.4 \\
\hline & & & (moderate) & $(S \tan 1)$ \\
\hline \multirow[t]{2}{*}{ Non-Reikists between 45 years and more $(n=37)$} & 53.85 & 42.95 & & \\
\hline & (high) & $(S \tan 2)$ & & \\
\hline \multirow[t]{2}{*}{ Reikists between 45 years and more $(n=31)$} & & & 39.9 & 34.1 \\
\hline & & & (moderate) & $(S \tan 1)$ \\
\hline \multicolumn{5}{|c|}{ Indicators according to the gender factor } \\
\hline \multicolumn{5}{|l|}{ Males $(n=116)$ among which: } \\
\hline \multirow[t]{2}{*}{ Non-Reikists $(n=89)$} & 56.67 & 42.1 & & \\
\hline & (high) & $(S \tan 3)$ & & \\
\hline \multirow[t]{2}{*}{ Reikists $(n=27)$} & & & 32.6 & 30.2 \\
\hline & & & (moderate) & $(S \tan 1)$ \\
\hline \multicolumn{5}{|l|}{ Females ( $n=222$ ) among which: } \\
\hline \multirow[t]{2}{*}{ Non-Reikists $(n=186)$} & 60.48 & 44.25 & & \\
\hline & (high) & $(S \tan 3)$ & & \\
\hline \multirow[t]{2}{*}{ Reikists $(n=36)$} & & & 37.6 & 32.8 \\
\hline & & & (moderate) & $(S \tan 1)$ \\
\hline
\end{tabular}

Note: AV: Average-arithmetic Value; SSWB: Scale of Subjective Well-Being; STAI: State-Trait Anxiety Inventory.

\section{Discussion}

The results found in this investigation are in complete accordance with the previous findings (the most recent ones were mentioned in the literature review of this study), which also indicate a positive relationship between Reiki techniques and psycho-emotional well-being. It can be confirmed that, on the one hand, practicing Reiki (various sports, either), as means for psychosomatic re-stabilization of health, can improve psycho-emotional well-being and vitality, and on the other hand, the increased vivacity, better mood, and enhanced internal energy, may have, in turn, a positive impact on vital functions and psycho-physiological activity. The comparative analysis of this research revealed differences between the groups of respondents of different professional specifications.

Young individuals, basically, had an orientation towards knowledge, self-development, advancing ideas and high levels of social activity. Herein, the differences in the sphere of personal growth, self-acceptance, and their relationships with others are observed among the students of all groups. Psychologists tend to be more self-oriented, with a more developed internal locus-control, for them, the health and self-confidence values are very important. Lawyers are focused on finding external causes for the events happening in their lives. The most pronounced characteristics in the groups of psychologists and sociologists are the value orientation, self-esteem, and a view on human nature. Student-athletes are often oriented towards personal success in sports, competitiveness or cooperation. With that, they are constantly involved in the field of sports and physical activities, which develop organizing, recreational, and anti-stress functions that increase with higher sport qualifications and the coming of age. From the point of view of the researchers of this study, precisely due to this, they showed lower degrees of anxiety and higher indicators of subjective well-being (relatively to all other youth non-Reikist groups). 
It was unexpectedly discovered that younger participants (senior pupils and college freshmen) had the worst indicators of anxiety and emotional well-being. With that, young organisms must be stronger, healthier, more resilient and more enduring. It is believed by the researchers that a significant part of Ukrainian students have the following problems: (1) already in the first years of study, students often come become disappointed with their chosen field, mostly because of the difficulties they have in their in relationships (with their fellow students and teachers), the need to assimilate huge amounts of educational information (frequently unnecessary and superfluous), ineffective innovations in the educational system; all these naturally led to chronic academic failure in studies; (2) as a result of huge and varied overloads and problems (associated not only with studies, but also with parents, poorly organized lives, their relationship with the opposite sex), many students experience stress (sometimes turning into neurosis) and are unable or do not know how to deal with it on their own; and (3), the current political and economic situation in Ukraine is the main destabilizing and stressful factor, therefore young individuals feel insecure in successfully finding jobs: in recent years, the standard of living of the Ukrainian population has declined significantly, there are difficulties in the industrial spheres, and, the most important factor, the unstable (military) conditions in the east of Ukraine.

Concerning the non-Reikist groups of middle-aged individuals (Research institute staff and Banking professionals), their indicators were better than those obtained with the groups of young individuals. This fact can be explained as follows: research institute staff are constantly involved in creative, puzzling, inspiring, and concentrating work, thus, efficiently abstracting from several external problems (difficult socio-political situation in the country, low salaries, etc.). Banking professionals work in a comfortable, favorable psycho-emotional atmosphere, having in addition better financial support (salaries and guaranteed social assistance), therefore they feel confident and psycho-emotionally stable.

All aforementioned problems affect, primarily, the emotional state of a person. Emotions, as a driving force of unified psycho-physiological process, are involved in the regulation of different body functions. Emotions are reflected on the person's psychological and mental state. They are expressed in external reactions and somatic-physiological characteristics of his or her self-feeling. The image-behavioral manifestation of emotion is formed on the basis of internal psycho-physiological reactions, caused by a physiological arousal. At the same time, a person's appropriate mimic-behavioral reaction is created, being an external form of reflection on an emotional stimulus. Emotions are involved in the process of assessing a particular situation by a person when he or she realizes and evaluates the possibility of satisfying his or her own needs. The ongoing emotional mood is related to the way he or she logically assesses such situation. Creating a sense of wellbeing/discomfort and the resulting good/bad health conditions depends on mood. Emotions are involved in the process of goal setting and the general regulation of human behavior, namely, while fulfilling the external behavioral act and expressing internal feelings which, in turn, create a comfortable/uncomfortable mood.

Such algorithm for creating a positive emotional background and internal stability is enhanced through the use of Reiki techniques. The hands (bent in the shape of a hemisphere and put to the acupuncture points of the body during a Reiki session) contribute to the stabilization and improvement of the person's energy field (or aura), whose existence has long been confirmed by numerous physical studies. As physicists have established, each human organ has its own resonant frequency, which can be registered by the corresponding radiation receivers. So, a focused impact on a particular organ of a human body by means of certain electromagnetic waves will lead to the activation of the functioning system of this organ (but such impact must be at specific resonant frequencies, with the correct power of radiation and for a certain period of time). Basing on the aforementioned, an analogical impact occurs during the practice of Reiki, when both hands are successively applied to specific areas of acupuncture and of chakras on the human body. In this case, the energy is concentrated in the chosen area of the body, the energy flow (along a specific energy meridian) is aligned and, at the same time, the functioning of the internal organs associated with this meridian improves. Thereby, a healing effect is achieved. 
The positive effects of the use of East Asian techniques, including Reiki, is based on the fact that all of them not only strengthen a person's protective-compensatory resources (without breaking the natural functioning of the body), as they also ensure this individual's psycho-stability, which gives a general positive effect. Several sessions of Reiki lead to mental balance, provide psycho-physiological harmony, strengthen the immune system, and fill the individual with a charge of emotions, energy, and enthusiasm.

\section{Conclusion}

The results of the Reikist group (with the average scores of 30 for the STAI and 35 for the SSWB) showed to be two times better than those of non-Reikists (with the average score between 50-35 for the STAI and 73-43 for the SSWB). It was found that Reikists showed the highest level of emotional comfort, lower levels of anxiety or dissatisfaction, a greater degree of optimism, self-confidence, vitality and energy that, in their totality, show more stable internal well-being levels, in comparison with all non-Reikist groups.

In particular, among the younger participants of non-Reikist groups, the senior pupils and university psychologists had worse results, while the average scores of the athletes group indicated a lower degree of anxiety and a better level of emotional well-being. So, the athletes possessed the best indicators among all young non-Reikists. Besides, the results of the older participants of non-Reikist groups (Banking professionals and Research institute staff) were significantly better when compared to all young non-Reikists.

On the sample of relatively healthy participants (not hospital patients), this study confirms that the practice of Reiki is a recreational, stimulating, motivating, as well as cost-effective technique, positively influencing to human well-being, mood, emotional and psychosomatic state: the use of Reiki self-healing techniques as a healing method helps individuals in obtaining a positive mental well-being and a healthy lifestyle. The results of the present study may serve as the basis for creating self-healing and health-oriented programs that might be applied not only in Ukraine, but in other countries too.

The main scientific relevance of this paper is to contribute to other studies, aimed at the improvement of the health conditions, cognitive development, and psychosomatic healing of individuals in society. These results are also relevant for a wider use of Reiki in traditional psychotherapy and hospitals as an additional treatment against stress effects and various health disorders. In addition, the dissemination of these results could increase the number of individuals who practice Reiki, which is consistent with the existing and evergrowing popularity of Reiki in Ukraine.

The prospective of the further investigations conducted by the authors of this paper is to study the psychological factors for providing the psycho-physiological strengthening and resistance of human organism, while applying a comparative cross-cultural approach and using different ethnic samples.

\section{Acknowledgments}

The author would like to thank Associate Professor E. ZAIKA, Senior Researcher I. IVANCHENKO, Professor L. GAZNIUK, and Professor M. BEILIN for their assistance in the collection of data.

\section{References}

Amirova, A., Cropley, M., \& Theadom, A. (2017). The effectiveness of the Mitchell Method Relaxation Technique for the treatment of fibromyalgia symptoms: a three-arm randomized controlled trial. International Journal of Stress Management, 24(1), 84-106. http://dx.doi.org/10.1037/str0000017 
Baldwin, A. L., Vitale, A., Brownell, E., Kryak, E., \& Rand, W. (2017). Effects of Reiki on pain, anxiety, and blood pressure in patients undergoing knee replacement: a pilot study. Holistic Nursing Practice, 31(2), 80-89. http://dx.doi.org/10.1097/ HNP.0000000000000195

Birocco, N., Guillame, C., Storto, S., Ritorto, G., Catino, C., Gir, N., ... Ciuffreda, L. (2012). The effects of reiki therapy on pain and anxiety in patients attending a day oncology and infusion services unit. American Journal of Hospice and Palliative Medicine, 29(4), 290-294. http://dx.doi.org/10.1177/1049909111420859

Bowden, D., Goddard, L., \& Gruzelier, J. (2010). A randomised controlled single-blind trial of the effects of Reiki and positive imagery on well-being and salivary cortisol. Brain Research Bulletin, 81(1), 66-72. http://dx.doi.org/10.1016/j. brainresbull.2009.10.002

Bowden, D., Goddard, L., \& Gruzelier, J. (2011). A randomized controlled single-blind trail of the efficacy of Reiki at benefiting mood and well-being. Evidence-Based Complementary and Alternative Medicine, 2011, e381862. http:// dx.doi.org/10.1155/2011/381862

Chang, E. C.-H., Chu, C.-H., Karageorghis, C. I., Wang, C.-C., Tsai, J. H.-C., Wang, Y.-S., \& Chang, Y.-K. (2017). Relationship between mode of sport training and general cognitive performance. Journal of Sport and Health Science, 6(1), 89-95. Retrieved from https://www.sciencedirect.com/science/article/pii/S2095254615001222

Erdogan, Z., \& Cinar, S. (2016). The effect of Reiki on depression in elderly people living in nursing home. Indian Journal of Traditional Knowledge, 15(1), 35-40. Retrieved from http://nopr.niscair.res.in/bitstream/123456789/33556/1/ IJTK\%2015(1)\%2035-40.pdf

Farias, C., Hastie, P. A., \& Mesquita, I. (2017). Towards a more equitable and inclusive learning environment in Sport Education: results of an action research-based intervention. Sport, Education and Society, 22(4), 460-476. Retrieved from https://pdfs.semanticscholar.org/b7f8/8b76c95d53d9d50e 099ba640c7f23020979a.pdf

Fuzhong, L., \& Harmer, P. A. (2014). Tai Ji Quan: from traditional applications to contemporary practice. Journal of Sport and Health Science, 3(1), 1-2. Retrieved from https://core.ac.uk/download/pdf/81968017.pdf

Ivanchenko, A. A. (2017). The positive summarized effect of the creative life-orientation phenomenon. Fundamental and Applied Researches in Practice of Leading Scientific Schools, 21(3), 100-107. Retrieved from https://farplss.org/ index.php/journal/issue/view/17

Ivanchenko, A., \& Zaika, E. (2017). Thinking and Personality's creative life-orientation: ways of development. Saarbrucken: Lap Lambert.

Ivanchenko, A., Timchenko, O., \& Zaika, E. (2018). How to get around the stress-traps in the students' life and avoid the stress acute angles. Science and Education, 3, 12-19. Retrieved from http://scienceandeducation.pdpu.edu.ua/ doc/2018/3_2018/2.pdf

Kovács, K. (2018). A comparison of factors influencing health risk behaviour of college students in the countries of the Carpathian basin. European Journal of Mental Health, 13(2), 184-210. Retrieved from http://real.mtak.hu/84430/

McManus, D. E. (2017). Reiki is better than placebo and has broad potential as a complementary health therapy. Evidence-Based Complementary and Alternative Medicine, 22(4), 1051-1057. http://dx.doi.org/10.11 $77 / 2156587217728644$

Midilli, T. S., \& Gunduzoglu, N. C. (2016). Effect of Reiki on pain and vital signs when applied to the incision area of the body after cesarean Section Surgery: a single-blinded, randomized, double-controlled study. Holistic Nursing Practice, 30(6), 368-378. http://dx.doi.org/10.1097/HNP.0000000000000172

Norchuk, Y., \& Lunov, V. (2016). Modeling of done early stability of personality in the context of understanding of life prospects (cadets sample). Fundamental and Applied Researches in Practice of Leading Scientific Schools, 14(2), 132-140. Retrieved from https://farplss.org/index.php/journal/issue/view/3

Notte, B. B., Fazzini, C., \& Mooney, R. A. (2016). Reiki's effect on patients with total knee arthroplasty: a pilot study. Nursing, 46(2), 17-23. http://dx.doi.org/10.1097/01.NURSE. 0000476246.16717.65

Perrudet-Badoux, A., Mendelsohn, G., \& Chiche, J. (1988). Développement et validation d'une échelle pour l'évaluation subjective du bien-être. Cahiers d'Anthropologie et Biométrie Humaine, 6(3-4), 121-134. Retrieved from https:// pascal-francis. inist.fr/vibad/index.php?action= getRecordDetail\&idt=11834895"idt=11834895

Reifsteck, E. J., \& Brooks, D. D. (2018). A transition program to help student-athletes move on to lifetime physical activity. Journal of Sport Psychology in Action, 9(1), 21-31. http://dx.doi.org/10.1080/21520704.2017.1303011

Rezaei, A., \& Khosroshahi, J. B. (2018). Optimism, social intelligence and positive affect as predictors of university students' life satisfaction. European Journal of Mental Health, 13(2), 150-162. http://dx.doi.org/10.5708/EJMH.13.2018.2.3 
Salles, L. F., Vannucci, L., Salles, A., \& Da Silva, M. J. P. (2014). The effect of Reiki on blood hypertension. Acta Paulista de Enfermagem, 27(5), 479-484. Retrieved from http://www.scielo.br/pdf/ape/v27n5/pt_1982-0194-ape-027-005-0479. pdf

Sokolova, M. V. (1996). The scale of subjective well-being. Yaroslavl: Psychodiagnostics.

Thrane, S., \& Cohen, S. M. (2014). Effect of Reiki therapy on pain and anxiety in adults: an in-depth literature review of randomized trials with effect size calculations. Pain Management Nursing, 15(4), 897-908. Retrieved from https:// www.ncbi.nlm.nih.gov/pubmed/24582620

Tsekhmister, Ya., \& Lysenko, O. (2018). The process of the future pharmacists' professional competence formation at the higher medical educational establishments. Fundamental and Applied Researches in Practice of Leading Scientific Schools, 25(1), 70-76. Retrieved from https://farplss.org/index.php/journal/article/view/275/253

Vasudev, S. S., \& Shastri, S. (2017). Effects of hands on Reiki on perceived stress and subjective wellbeing among software professionals in Bangalore. International Journal of Social Science and Humanity, 7(6), 362-366.

West, J., Liang, B., \& Spinazzola, J. (2017). Trauma sensitive Yoga as a complementary treatment for posttraumatic stress disorder: a qualitative descriptive analysis. International Journal of Stress Management, 24(2), 173-195. http://dx. doi. org/10.1037/str0000040

Received: July 5, 2019

Final version: December 17, 2019

Approved: February 2, 2020 